\title{
LA EPIGRAFÍA LATINA DE TERUEL. A PROPÓSITO DE UN NUEVO CORPUS PROVINCIAL
}

POR

\author{
FRANCISCO BELTRÁN LLORIS \\ Universidad de Zaragoza
}

\section{RESUMEN}

Revisión crítica del corpus de M. Navarro, La epigrafía de Teruel, Teruel, 1994.

\section{SUMMARY}

Critical review of the corpus by M. Navarro, La epigrafía romana de Teruel, Teruel, 1994.

El breve pero interesante conjunto epigráfico de la provincia de Teruel acaba de ser objeto de estudio y nueva recopilación en una cuidada monografía editada por el Instituto de Estudios Turolenses bajo los auspicios de las universidades de Zaragoza y Michel de Montaigne de Burdeos (III), La epigrafía romana de Teruel, Teruel, 1994 (191 pp., XVI láms., en lo sucesivo ERT), que incluye varios soportes anepígrafos, 27 inscripciones y una selección de los interesantísimos letreros rupestres de Peñalba de Villastar. Su autora, Milagros Navarro, joven investigadora formada en los dos centros universitarios mencionados y en posesión ya de un apretado curriculum, ha llevado a término un extenso trabajo que, además de catálogo (pp. 75-164), índices (pp. 175-189), aparato gráfico (XVI láminas) y unas breves conclusiones (pp. 165-173), contiene una extensa introducción histórica sobre la provincia de Teruel en la Antigüedad (pp. 33-57) y una pormenorizada revisión de la historiografía epigráfica a ella referida (pp. 57-74), con el interés añadido de ser la primicia de una nueva serie, PETRAE Hispaniarum, que, según se anuncia en el prólogo, irá editando en papel impreso y con los criterios utilizados en esta monografía las bases de datos informatizadas que dicho proyecto, animado desde Burdeos y con sedes en diversas universidades españolas, lleva confeccionando en los últimos años sobre la epigrafía latina peninsular.

Se trata, por lo tanto, de un trabajo que encierra múltiples puntos de atención y no pocos méritos en su planteamiento, pues contextualiza la serie epigráfica con un sucinto pero completo estado de la cuestión histórico y arqueológico, revisa de mane- ra crítica las tradiciones eruditas relativas a las inscripciones turolenses -con aportación de algún manuscrito inédito-, recurre a un interesante empleo de la informática como base de la catalogación, aborda con acierto el estudio global de los soportes y la cronología, y constituye, en definitiva, la primera recopilación de las inscripciones latinas turolenses -incluidas tres inéditas- realizada según las exigencias de la moderna edición epigráfica ${ }^{1}$. Sin embargo junto a estas aportaciones que ponen claramente de manifiesto la bondad del planteamiento general del trabajo y la competencia de la A. en la materia, esta nueva recopilación de la epigrafía turolense presenta vertientes menos satisfactorias, pues omite cinco epígrafes previamente publicados, aborda el conjunto de Peñalba de Villastar con criterios confusos -presentando como latinos rótulos sin duda celtibéricos- $y$, sobre todo, encierra abundantes imprecisiones en la descripción de los soportes, en las circunstancias del hallazgo y, a veces, en la presentación del texto de algunos epígrafes.

Dado el interés objetivo que tanto la monografía en sí como la serie que inaugura encierran y nuestro conocimiento directo de la epigrafía turolense ${ }^{2}$,

\footnotetext{
${ }^{1}$ Al margen de obras de carácter general que sólo recogían las inscripciones a título de inventario (como las utilí simas de J. Lostal, Arqueología del Aragón romano, Zaragoza, 1980 o P. Atrián, C. Escriche, J. Vicente y A. I. Herce, Carta arqueológica de España: Teruel, Teruel, 1980 $=C A T$ ), el único repertorio era el publicado por A. Ventura («Las inscripciones romanas e ibéricas de la provincia de Teruel», Teruel 54, 1975, 211-253 = Ventura), un trabajo no exento de interés, pero parcial y en muchos sentidos amateur (cf. la reseña de G. Fatás, «Notas para la catalogación de la epigrafía romana de Teruel», Teruel 57-58, 1977, 23 34 = Fatás). El corpus de Ventura reunía 17 epígrafes latinos, mientras que eran 23 los recogidos en $C A T$.

${ }^{2}$ Esta reseña es fruto de la revisión del trabajo de $\mathrm{M}$. Navarro con la finalidad de incorporarlo al manuscrito preparatorio de la nueva edición del CIL II $^{2}$, en la que desde 1980 venimos trabajando en Aragón M. Beltrán, F. Marco y quien subscribe. En lo que a la provincia de Teruel se refiere, de la que nos hemos ocupado más directamente F. Marco y yo mismo, algunas inscripciones han sido ya editadas en el fascículo dedicado a la parte meridional del convento tarraconense (G. Alföldy, M. Clauss y M. Mayer, eds., fasc. 14 Berlin, 1995), en concreto las procedentes de La Iglesuela
} 
hemos creído de interés redactar estas páginas con la finalidad de completar los datos presentados por la A., corregir algunas inexactitudes y añadir puntos de vista discrepantes, en la convicción de que la crítica, cuando es constructiva, redunda en un mejor conocimiento de la materia sobre la que versa.

\section{I}

A la completa síntesis histórica y arqueológica que sirve de introducción al corpus sólo cabe hacer un reparo: la falta de atención a la epigrafía paleohispánica ${ }^{3}$. Este déficit se deja notar sobre todo en el poco afortunado tratamiento del conjunto de Peñalba de Villastar (ERT 27), pero también en la interpretación de la onomástica indígena presente en algunas inscripciones latinas, caso de ERT 14 de Hinojosa de Jarque, cuyos antropónimos, Dirtanus y Elguanus, no son ibéricos -como asevera la A. en p. 168-, sino claramente célticos, por lo que, lejos de confirmar el carácter ibérico de la parte central de la provincia o de permitir afirmar que la mayor parte de ella fuera ibérica (p. 37), sugieren la posibilidad de que la Sierra de San Just, en el centro de la provincia, marcara el límite entre los espacios lingüísticos ibérico -uniforme al Este de la línea que va de Oliete y Alloza hasta La Iglesuela del Cid- y celtibérico -con los centros más orientales en $\mathrm{Ca}$ minreal y Peñalba-, en concordancia con la antroponimia de los epitafios latinos de Alcañiz (ERT 5), ibérica, y de Cella (ERT 10), celtibérica, si bien, al tratarse de una inscripción del Principado -en la que, además, no se hace constar la origo de los individuos- no resulte prudente extraer de ella conclusiones definitivas.

Las páginas dedicadas a examinar la tradición

del Cid, localidad que durante el Principado pertenecía presumiblemente al territorio de Lesera (El Forcall, Castellón): CIL $\mathrm{II}^{2}, 14,775-780$ con fichas redactadas por G. Alföldy, F. Marco y F. Beltrán. En la actualidad y prescindiendo del conjunto de Peñalba, son 37 las inscripciones de las que tenemos noticia: junto a las 27 recogidas por Navarro -su núm. 31 en realidad no es anepígrafa, pues conserva leves restos del epígrafe- y las cinco que omite, hay que señalar otras cinco inéditas: el fragmento aparecido hacia 1990 en la catedral de Albarracín, y el hallazgo con posterioridad a la fecha de publicación de su monografía de los dos primeros miliarios de la provincia, en San Blas (J. Vicente y B. Ezquerra, «Informe sobre las excavaciones de urgencia en 'Masía del Cantor', Teruel», Arqueología aragonesa, en prensa) y Jatiel, y del interesante fragmento de La Puebla de Híjar (L. Gimeno y C. Gimeno, «Una nueva inscripción de La Puebla de Híjar, Teruel», Kalathos, en prensa) que permite defender la reducción a dicha localidad de Osicerda (F. Beltrán, «Una liberalidad en La Puebla de Híjar (Teruel) y la localización del municipium Osicerda», en este mismo volumen de $A E \operatorname{spA}$ ). erudita y los estudios científicos sobre las inscripciones turolenses contienen una dura y, a mi juicio, inmerecida crítica de los trabajos tanto de Emil Hübner («el sabio alemán las presentó con errores. No las vio personalmente, sino que utilizó los escritos de los eruditos aragoneses, confundiendo sus palabras», p. 57) cuanto de Cabré, Gómez Moreno y Tovar sobre Peñalba de Villastar («...presentaron con errores todos los textos», p. 72). Lo cierto es que el sabio hispanista alemán, a pesar de la magnitud de su tarea, de las condiciones de trabajo imperantes a fines del siglo xIX y de no haber dispuesto de la oportunidad de ver los epígrafes en persona, dio versiones de los textos bastante correctas en general y realizó una revisión ingente de la tradición manuscrita y erudita, mientras que las aportaciones de Cabré, Gómez Moreno y Tovar sobre Peñalba, un conjunto de extraordinaria dificultad que todavía aguarda una adecuada y sistemática investigación interdisciplinar que resuelva los múltiples problemas que plantea, aun siendo deficientes en algunos sentidos, no son mejoradas en ERT 27, cuyas versiones de los textos son idénticas a las de Tovar y Gómez Moreno casi siempre ${ }^{4} \mathrm{y}$, a cambio, especulativas (caso de ERT 27O, 27P siguiendo a Lejeune, 27Q siguiendo a Mallon) o inexactas (ERT 27A), cuando la $\mathrm{A}$. se aleja de ellas, con la única excepción de ERT 27I. Añádase que tanto ERT 27J cuanto ERT $27 \mathrm{~K}$, que toma de Untermann, son transcritas sin reparar en algunas precisiones fundamentales del sabio paleohispanista alemán y que en ERT 27L atribuye a F. Marco un desarrollo que no consta en el artículo citado ${ }^{5}$.

La revisión de la tradición erudita, una tarea ingrata, pero imprescindible y de gran relevancia no sólo en el caso de los epígrafes conocidos desde antiguo y posteriormente perdidos -por fortuna sólo

${ }^{3}$ Sobre las inscripciones ibéricas puede consultarse el completo corpus de J. Untermann, Monumenta linguarum Hispanicarum, III, Wiesbaden, 1990, t. 2, pp. 179 ss.; para las célticas, aparte del conjunto de Peñalba, hay que destacar el interesantísimo grupo de letreros exhumados en las excavaciones de La Caridad de Caminreal: J. Vicente y otros, «Las inscripciones de la Casa de Likine-te», en F. Villar y J. Untermann, Lengua y cultura en la Hispania prerromana. $V$ Coloquio sobre lenguas y culturas paleohispánicas, Köln, 1989, Salamanca, 1993, 750-772, que incluye el ya famoso rótulo musivo en lengua y escritura ibéricas que es el único mencionado por la A., p. 47 nota 49 , por cierto con un error en la transcripción del último término del texto que es usekeŕteku y no 'usekerku'.

${ }^{4} \mathrm{Cf}$. ERT 27B, 27C, 27D, 27E, 27F, 27G, 27H, 27M con un error, $27 \mathrm{~N}$; aunque separando como epígrafes independientes algunos que Tovar y Gómez Moreno consideraban pertenecientes al mismo texto.

${ }^{5} \mathrm{~F}$. Marco, «El dios céltico Lug y el santuario de Peñalba de Villastar», Homenaje al Dr. A. Beltrán Martínez, Zaragoza, 1986 , p. 746. 
cinco en la provincia de Teruel: ERT 1, 2, 10, 18 y 24-, sino también para precisar la fecha, el lugar de hallazgo y otros pormenores interesantes de los aún conservados, presenta luces y sombras. Hay aportaciones de interés a propósito de los epígrafes de Albarracín, Calomarde, La Iglesuela del Cid o Rubielos de Mora -incluida la exhumación del manuscrito desconocido del canónigo Collado con noticias sobre las inscripciones de Albarracín- y, como es habitual entre los estudiosos modernos, se toma en consideración el testimonio, ignorado por Hübner, de Juan Bautista Lavaña en Itinerario del reino de Aragón -obra que es preferible consultar en la interesante edición del original realizada por iniciativa de la Diputación Provincial de Zaragoza ${ }^{6}$ y no en su versión traducida al castellano-, cuya actividad merecería un estudio más detenido desde la óptica epigráfica, habida cuenta de la llamativa coincidencia existente entre sus versiones de los epígrafes y las recogidas por Zurita. A cambio han sido descuidadas obras recientes de eruditos locales como la de Sancho a propósito de Alcañiz, con una inscripción de Castelserás ignorada por los estudiosos modernos, o la de Aguirre sobre Cella, en la que ya se da noticia de ERT 11 -que, por lo tanto, no es inédita, ni aparecida en la fecha que indica la A.-, y asimismo los datos sobre la procedencia de los epígrafes conservados en Calomarde (ERT 8 y 9) y Torremocha (ERT 25) que no aparecieron en estas localidades, sino que fueron trasladados hasta ellas desde Moscardón y Aguatón respectivamente.

\section{II}

En lo que respecta al modelo de ficha que la A. utiliza en la catalogación se trata del vertido directo, aunque extractado, de la base de datos informática del programa PETRAE (pp. 23-25). Este procedimiento, utilizado ya en otros corpora ${ }^{7}$, entraña incuestionables ventajas en lo que se refiere a la sistematicidad y la homogeneidad en la presentación de la información, pero conlleva también algunos inconvenientes: en particular, la acusada compartimentación y la reiteración de algunos datos (caso de los relativos al descubrimiento y lugar de conservación o a la decoración) no siempre facilitan la localización de la información deseada y alargan en exceso la descripción con una treintena de entradas repetidas en cada inscripción (Lugar del desc., Con-

${ }^{6}$ J. B. Lavaña, Itinerario del reino de Aragón, Zaragoza, 1895 = Lavaña

${ }^{7}$ Caso del editado por L. Maurin con M. Thauré y F. Tassaux, Inscriptions Latines de l'Aquitanie (I.L.A.). Santons, Bordeaux, 1994. texto local, Cond. del desc., Lugar de conserv., Inst. de Conserv., etc.), imprescindibles sin duda en la ficha informática dividida en campos, pero superflua -o al menos simplificable- en un libro. Particularmente clara es esta servidumbre informática en el apartado cronológico, en el que se ha optado por expresar la fecha siempre mediante dos guarismos exactos (p. ej., 81/150), necesarios seguramente para el tratamiento informático de estos datos-que, por cierto, sería útil explicitar-, pero que transmiten una falsa impresión de certidumbre, cuando en realidad son tan convencionales como las expresiones tradicionales («fines del siglo I o primera mitad del segundo») y que, además, no siempre resultan transparentes aunque se hagan explícitos los criterios que las fundamentan: por ejemplo, el terminus post quem de ERT 9, fijado en 81 d. E., se justifica diciendo que la ornamentación que decora el soporte comienza a utilizarse en época flavia, aunque esto no aclare por qué la fecha inicial elegida sea el año 81 y no el 70, por ejemplo. Quizás fuera preferible en ulteriores monografías de esta serie prescindir de la comodidad que supone el vertido automático desde la base de datos y redactar de nuevo estas secciones pensando en el lector: la información no perdería en densidad y a cambio ganaría mucho en concisión y claridad.

De sus diferentes apartados, los referidos a la descripción del soporte y a la ubicación y maquetación del texto sobre él, incluyendo la altura de «los interlíneos» -en castellano, mejor interlíneas-, muy minuciosos y sistemáticos, constituyen uno de los aspectos más positivos de las normas de edición PETRAE. En todo caso, cabría distinguir -por ejemplo mediante paréntesis- las medidas fragmentarias, sistematizar el tratamiento de las interpunciones y señalar la fecha en que fue realizada la autopsia de la pieza. En lo que se refiere a la bibliografía, quizá sería de utilidad ampliar a las publicaciones modernas la indicación de las dependencias entre unos y otros autores, así como la existencia o no de autopsia y, en este último caso, el origen de la información. La presentación del texto se realiza utilizando los signos diacríticos habituales, con excepción de los semicorchetes $(\Gamma\urcorner)$ que se reservan para las correcciones realizadas exclusivamente sobre copias o manuscritos poco fiables, y no para la corrección por el editor de letras grabadas por error. No se indican, a cambio, las letras hoy perdidas, pero conservadas en lecturas previas, fotografías o dibujos, que en otras ediciones se presentan subrayadas ${ }^{8}$.

${ }^{8}$ S. Panciera, «Struttura dei supplementi e segni diacritici dieci anni dopo», Supplementa Italica 8, Roma, 1991, pp. 921 . 
En cuanto a la ordenación de los textos se ajusta al orden alfabético de las localidades en que aparecieron los epígrafes, relegando los soportes anepígrafos al final. En el caso de Teruel, dada la limitación del corpus y que hasta la fecha no ha sido posible identificar ninguna de las ciuitates que, suponemos, se localizaban en la provincia -con excepción de lo dicho sobre Osicerda en la nota 2-, esta presentación no entraña problemas y facilita la localización de los epígrafes, aunque supone la separación de inscripciones que presumiblemente pertenecían en la Antigüedad a la misma comunidad (p. ej. Albarracín, Moscardón / Calomarde y Torres de Albarracín), por lo que quizás en ulteriores volúmenes de la serie PETRAE Hispaniarum que afecten a espacios regionales o provinciales conviniera reconsiderar este criterio. No se hace constar, sin embargo, cuál es el criterio aplicado a la hora de integrar o descartar los epígrafes sobre instrumentum, de los que se recogen sólo las tesserae hospitales, pero no los rótulos sobre cerámica u otros soportes que, a cambio, en el corpus dedicado a Santons, también elaborado siguiendo las normas PETRAE, ocupan un lugar muy importante ${ }^{9}$.

En lo que se refiere a la confección del corpus, hay que destacar el positivo tratamiento de la cronología y de la morfología de los soportes. Al margen de lo dicho sobre el uso de guarismos exactos, la A. ha resuelto con acierto la datación del conjunto, materia siempre delicada, combinando todos los elementos de juicio disponibles (onomásticos, formularios, paleográficos, relativos al soporte o al material del mismo), por más que en algunos casos sean discutibles - como en Peñalba-o que la fundamentación de la cronología en principios generales pudiera haber sido matizada y contextualizada a partir de otros conjuntos hispanos, próximos y mejor conocidos como, por poner un ejemplo, ocurre con la presencia o ausencia de la consagración a los dioses Manes -que parece utilizarse como hito fijo, aunque desde luego no único, para datar los epígrafes antes o después de 100 d. E.-, cuando es evidente que dicha fórmula se utiliza con anterioridad a esa fecha ${ }^{10}$ y no aparece de manera sistemática después. Hubiera sido quizá de utilidad el recurso a un criterio de datación que ha resultado operativo en conjuntos bien fechados y relativamente próximos de Levante y la costa catalana. $\mathrm{Me}$ refiero al que se deriva del uso de recuadros moldura-

\footnotetext{
${ }^{9}$ Maurin 1994 (cit. n. 7), núms. 1001, 1 ss., de los que precisamente el núm. 1004,5 ha sido redactado por M. Navarro.

${ }^{10}$ Ver, por ejemplo, A. U. Stylow, «Los inicios de la epigrafía latina en la Bética», en F. Beltrán (ed.), Roma y el nacimiento de la cultura epigráfica en Occidente, Zaragoza, 1995 , p. 223.
}

dos enmarcando el texto que en Tarraco, por ejemplo, pero también en la Bética, aparecen en los epitafios a partir de mediados del siglo i d. E. ${ }^{11}$ y que, en consecuencia, aconsejan rebajar las dataciones a partir del año $1 \mathrm{~d}$. E. que la A. atribuye a ERT 3, 14, 25 y 26. Obsérvese que en los conjuntos conservados en La Iglesuela y Calomarde, datables grosso modo entre fines del siglo I y el siglo II, este criterio encaja perfectamente. A cambio, la A. rectifica con razón la atribución cronológica a los siglos II o III de las estelas de Puertomingalvo (ERT 22, 23, 31 y 32), que prefiere datar en el I d. E. En efecto, éstas conforman junto con el epitafio de Alcañiz (ERT 5), el de Hinojosa de Jarque (ERT $13^{12}$ ) y el torpe epitafio de la Puebla de Valverde (ERT 21) un conjunto relativamente uniforme pese a las diferencias formales en el soporte. Todas estas piezas coinciden en sus formularios y son, por todo ello, fechables a lo largo del siglo i d. E. ${ }^{13}$. Coincido en lo fundamental en las restantes dataciones propuestas por la A. con la excepción de la atribuida al árula funeraria de Alcañiz (ERT 7), que sitúa por indicios paleográficos entre 251 y 400: es evidente que la pieza no es temprana pero, dado el carácter fragmentario del texto, prefiero no pronunciarme.

A cambio, sobre la presentación de los datos materiales, de hallazgo y conservación la valoración de conjunto no puede ser tan positiva, pues son demasiado frecuentes las omisiones, las inexactitudes o los errores. Sin pretensiones de exhaustividad, hay que introducir correcciones o faltan datos de interés al menos en ERT 1, 3 , $7,8,9,11,12,13,14,20,21,22,24,25$, 26, 27, 28 y 31. En unos casos se trata de atribuciones geográficas incorrectas como las más arriba señaladas a propósito de ERT 8 y $9^{14}$,

${ }^{11}$ G. Alföldy, Die römischen Inschriften von Tarraco, Berlin, 1975, pp. 470 ss.; Stylow 1995 (cit. n. 10), pp. 224 y 226; con una cierta antelación figuran en algunos epígrafes honoríficos, caso de CIL I ${ }^{2} 2673$ de Barcino, tradicionalmente considerada como republicana, pero probablemente augustea: cf. M. Mayer, «El primer horizonte epigráfico en el litoral Noreste de la Hispania citerior», en Beltrán (ed.), 1995 (cit. n. 10), p. 100 fig. en pág. 108.

${ }^{12} \mathrm{Cf}$. los claros paralelos béticos mencionados por Stylow 1995 (cit. n. 10), p. 223

${ }^{13} \mathrm{~F}$. Beltrán, «La escritura en la frontera: inscripciones y cultura epigráfica en el valle medio del Ebro», en Beltrán (ed.), 1995 (cit. n. 10), p. 186: presentan los nombres de los difuntos en nominativo, con filiación, e hic situs est -salvo ERT 22-, y en las tres últimas la indicación de la edad.

${ }^{14}$ Estas piezas fueron vistas, en efecto, por Lavaña (pp. 148-149) en Calomarde a comienzos del xVII; sin embargo, como Hübner (CIL II 3172) y CAT p. 190 indican, Zurita había examinado a mediados del xvi en Moscardón cuando menos ERT 8, que debió ser trasladada a comienzos del XVII desde esa localidad a Calomarde, quizás con motivo de la remodelación de la iglesia de San Pedro Apóstol que data de esas mismas fechas. 
y $25^{15}$. En otros son imprecisos los datos relativos al lugar y la fecha de descubrimiento (ERT 11 y 26), faltan medidas (ERT $1^{16}, 12^{17}, 27$ y $28^{18}$ ) o son inexactas (ERT 11, $13^{19}, 14^{20} 20^{21}, 21^{22}, 22^{23}$, $28^{24}, 31^{25}$ ) o bien hay elementos del soporte mal descritos (ERT $3^{26}, 7^{27}, 20^{28}$ y $24^{29}$ ). En otros casos se han deslizado incorrecciones o contradicciones en los comentarios o en la bibliografía que con-

${ }^{15}$ Esta pieza conservada en Torremocha procede de Aguatón (así, en CIL II 3170, Ventura, núm. 2 y CAT p. 57), pues, como refiere Campillo, apareció en 1804 «en el término de Torremocha, partido de Teruel, a dos horas del dicho pueblo (no «a $2 \mathrm{~km}$.») y confines de el de Torre-la-carcel y Villar-quemado, camino de $\mathrm{N}^{\mathrm{a}} \mathrm{S}^{\mathrm{a}}$ del castillo del lugar de Aguatón».

${ }^{16}$ Totales: $45.5 \times 76.5 \times-$

17 Totales: $9 \times 9,5 \times 2-0.4$

${ }^{18}$ Campo epigráfico: $3.9 \times 13.1$.

${ }^{19}$ La cartela mide $19 \times 30.5$ (no « $28 \times 18 »$ ); las letras no son uniformes de $3 \mathrm{~cm}$., pues son varias las de menor tamaño.

${ }^{20}$ Totales: (55) x (75) x (39); no «54 x 57»

${ }^{21}$ Altura de las letras: 1. $1^{\text {a }}$ 6-6.5; resto: $4.5-5.5$ (no entre 4.5 y 5$)$.

${ }^{22}$ Totales: (34) x (29.5) x 4 (no «144 x $\left.42 \times 13.5 »\right)$.

${ }^{23}$ Totales: $100 \times 29 \times 8$ (no «10 × $29 \times 8$ ×

24 Totales: $5.5 \times 13 \times 2.2$ (no, «43 x 145»).

25 Totales: $(60) \times 36.5 \times 16.5$ (no «595 × $37 \times 165 »)$.

${ }^{26}$ La decoración no consiste en una roseta, pese al testimonio de Lavaña, sino en una corona como todavía se puede apreciar sobre la piedra.

27 Decorada con una estrella de ocho puntas, no de seis.

${ }^{28}$ La estela es de caliza, no de arenisca.

${ }^{29}$ Las medidas suministradas por Lavaña corresponden aproximadamente a $84 \times 63 \times 6$.

${ }^{30}$ A propósito de la tésera de Fuentes Claras (quom Metellilneis tessera), ya C. Castillo señaló su patente semejanza con la procedente de Cáceres que se data hacia 70 a. E. (h. f. quom Elandorian?), pero también las diferencias entre ambas piezas («De epigrafía republicana hispano-romana», en G. Fatás, ed., Epigrafía hispánica de época romano-republicana, Zaragoza, 1986, pp. 145-146, mal citado por la A. que, además, atribuye a Castillo una identificación de los Metellinei con los soldados de Metelo que la prof ${ }^{a}$ Castillo señaló en otro lugar-SHDI 52, 1986, p. 369- y que, precisamente, matizó en el coloquio zaragozano). La interpretación de estos Metellinei con un grupo de clientes de Metelo que defiende la A. me parece poco satisfactoria, no sólo por la inverosimilitud de que, por estas fechas (c. 70 a. E.), existiera una nutrida clientela de Metelo en esta zona de la Celtiberia, sino sobre todo porque supone que actuaba como una entidad jurídica compacta. Creo más probable que Metellinei fuera una manera de denominar a Metelo y sus descendientes (paralela al formulario del Principado hospitium fecit.. sibi, liberis, posterisque eius), a semejanza de la denominación de los grupos familiares celtibéricos mediante formas adjetivales derivadas de un antropónimo (J. Gorrochategui, «Consideraciones sobre la fórmula onomástica y la expresión del origen en algunos textos celtibéricos menores», en F. Villar, ed., Studia Indogermanica et Palaeohispanica in honorem A. Tovar et L. Michelena, Salamanca, 1990, p. 299 nota 17 proponiendo que el sufijo -ino fuera un trasunto del celtibérico -ico; Beltrán 1995 (cit. n. 13), p. 179).

${ }^{31}$ Debe rectificarse el título de esta ficha «Ofrenda de dos esclavos a Hércules», pues como la $\mathrm{A}$. defiende con acierto, no se trata de dos esclavos de Cornelio, sino de dos individuos cuyo nomen postpuesto es Cornelius. La primera edi- vendría también corregir o matizar como en ERT $12^{30}, 20^{31}, 23^{32}, 28^{33}$.

\section{III}

Es de lamentar que en una serie tan corta hayan escapado a la atención de la A. al menos cinco epígrafes ya publicados, de los que doy cuenta en otro lugar ${ }^{34}$, por lo que aquí me limitaré simplemente a mencionarlos: el epitafio perdido de Castelserás, aparecido en 1743 y recogido por Sancho ${ }^{35}$; el epígrafe fragmentario, también perdido, hallado hacia 1953 en Alcañiz que publicara A. Beltrán ${ }^{36}$; la tessera nummularia de La Iglesuela del Cid dada a conocer en 1977 por G. Alföldy ${ }^{37}$; el grafito sobre un plato de terra sigillata itálica exhumado en San Esteban (El Poyo del Cid) por F. Burillo en $1978^{38}$; $\mathrm{y}$, por último, el sello sobre mortero recuperado en

ción del texto es de Ventura, no de A. Beltrán, que se limitó a señalar su existencia en el castillo de Manzanera.

${ }^{32}$ Tampoco el título «Una mujer de Edeba en Puertomingalvo» ni el comentario «nació en Edeba...» son acertados. Sulpicia Sex f. domo Edeba no hace constar su origo, sino su domicilium (en este sentido ya Fatás, pp. 26-27). Según Ptolomeo (II 6, 63), "A $\delta \varepsilon \beta \alpha$ no era una ciudad de los ilerge-

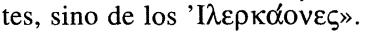

${ }^{33}$ Falta la referencia a la excelente ficha de A. Degrassi (CIL $\left.\mathrm{I}^{2} 3465\right)$, en donde ya da como procedencia el ilocalizado lugar de Castillo (no «El Castillo», cf. el expediente de ingreso en el MAN, 1928 / 108) y desarrolla correctamente la abreviatura Mai(cia) -como de hecho lo hiciera previamente M. Koch, «Die Turulli und Neukarthago», Nauicula Tubingensis. Studia in honorem Antonio Tovar, Tübingen, 1984 , pp. 243-246-, que no son, por lo tanto, primicias que pueda atribuirse la A. En lo que respecta a la identificación del personaje, P. Turullius P. f. Mai(cia), como defendiera Koch, debe ser un miembro de la familia itálica (¿marsa?) relacionada con la explotación del plomo cartagenero, quizás hijo del $P$. Turullius M. $f$. Mai. de la massa plumbea murciana y padre del dunviro cartagenero de época tardoaugustea o tiberiana (pero no el asesino de César al que alude Cass. Dio LIX 8, 2 ss., identificación que en ningún momento propone Koch), en cuyo caso le cuadraría bien una fecha a mediados del siglo I a. E. La suposición de la A. de que fuera un magistrado de rango ecuestre debe ser un lapsus.

${ }^{34}$ F. Beltrán, «Epigrafía romana (1987-1993)», Caesaraugusta, en prensa.

${ }^{35}$ N. Sancho, Descripción histórica artística detallada y circunstanciada de la ciudad de Alcañiz y sus afueras, Alcañiz, 1860 , pp. 365-366 con el texto ATILIA | SP.VRI.F | LVCILLAE | M. ANTONIVS । NACHVS.VXORI, que puede rectificarse verosímilmente en la forma Atiliae | Spuri॰f | Lucillae | M•Antonius | [il]nachus•uxori.

${ }^{36}$ HAEp 4-5, 1953-1954, 731: -----| [---]STI[---] । [---]X $[--]_{37}$ I G. Alfö Fauentini.

${ }^{38}$ F. Burillo, «Sobre unos fragmentos de Terra Sigillata Itálica hallados en el yacimiento de San Esteban, El Poyo del Cid, Teruel», Teruel 63,1980 , pp. $42-43$ y fig. 2 con dibujo; $C A T$, p. 203 núm. 431: Beneuoli, trazado sobre un plato de la forma Goudineau 39 (con sigillum GAVI), entre el cambio de Era y el año 40 d. E. 
las excavaciones dirigidas por J. Vicente en $\mathrm{La} \mathrm{Ca}$ ridad de Caminreal ${ }^{39}$.

En lo tocante a los epígrafes recopilados por la A. en el corpus cabe realizar las siguientes observaciones.

ERT 1 (lám. I, 1a-b). Albarracín. La novedad a propósito de este sospechoso epígrafe perdido radica en el testimonio, exhumado por la A., del canónigo Collado quien, en dos obras manuscritas de comienzos del XIX, da a entender que todavía resultaba visible en sus días y lo dibuja junto a un sillar decorado con pátera y preferículo que se conserva en la base de la torre de la catedral, muy cerca de ERT 3 y 4. Por desgracia, el valor de la noticia de Collado queda muy reducido por no ser fruto de una autopsia directa, sino -como la A. señala- transcripción de la versión, muy libre e imaginativa, de Masdeu, que como las restantes depende, a través de Traggia y Uztarroz, del testimonio de L. Martínez. Es muy sospechoso que Zurita y Lavaña, que dan noticia de ERT 2, 3 y 4 y que visitaron Albarracín en el siglo XVI y a comienzos del XVII, ignoren este epígrafe y que, además, sobre el soporte que dibuja Collado no se aprecie hoy rastro alguno de inscripción, a diferencia de ERT 3 y 4, mal conservados pero con restos claros de escritura. Por todo ello nos inclinamos a considerar este texto más probablemente falso -fruto seguramente de un exceso de imaginación de Collado o de su deseo de incrementar las antigüedades patrias- que interpolado (que es lo que pensaba Hübner CIL II 5889), duda similar, por cierto, a la que pesa sobre otro epígrafe dedicado a Diana recogido en el Codex Valentinus (CIL II 3168) con el texto Dianae I Titus Mevius I f•v•s•, supuestamente procedente de un lugar «non procul a Tagi fluvii fonte»y, por lo tanto, quizá próximo a Albarracín. En consecuencia resulta poco productivo intentar restituir el comienzo del texto transmitido (Dian[---]EDS[---]LIBIDI sac[rum] I PRO.SALVT... I VIR..HON...RIN... I EX VOTO), que la $\mathrm{A}$. propone entender en la for-ma Dian[a]e 'et' [Apo]IIITrni sac[rum], con una invocación bastante inhabitual, como ella misma reconoce (p. 80), que exige una fuerte corrección de un texto sospechoso y constituye sólo una posibilidad exempli gratia (por ejemplo, cabría también leer Ts 'sidi al comienzo de la 1. 2). Habida cuenta de que la tradición que conservamos no resulta fiable, creo preferible

${ }^{39} \mathrm{~J}$. Vicente y otros 1993 (cit. n. 3), pp. 759-762 con dibujos y fotografías. La lectura más probable es $\mathrm{Fl}$ (accus ?)•Atili I L(uci)•s(eruus). No es un producto local, sino procedente de un taller ilocalizado, activo a fines del II y comienzos del I a. E. y situado hacia el Bajo Ebro. presentar el texto tal como ésta lo ha transmitido, expresando las serias dudas existentes sobre su autenticidad.

ERT 2. Albarracín. Sobre este epígrafe perdido, es de gran interés -como señala la A.- el testimonio de Lavaña ${ }^{40}$, pues permite identificarlo como una dedicatoria y no como un miliario, que fue como lo entendió Hübner (CIL II 4916; EE 9, 1903, núm. 318). En lo que al texto se refiere, creo preferible la tradición, más antigua y de mayor calidad, que se remonta a Zurita y Lavaña ([---]DIO CAE । [---] GERM । [---] MAXIM । [---] IMP III), y apunta a Claudio, que la que se inicia con Uztarroz y siguen Traggia, Masdeu y Collado que intenta identificar al emperador con Claudio II el Gótico -aunque con una titulatura anómala ${ }^{41}$ - ([---]DIO GAE I [--]G GERM I [---]I MAX TRI I [---]T IMP IIS), que la A. prefiere rectificar y combinar con la anterior, aun inclinándose también por atribuir el epígrafe a Claudio. En cualquier caso, la inscripción debe datarse en $41-\mathrm{o}$ a lo sumo a comienzos de enero de $42-$ y no en $41 / 43$, puesto que Claudio revistió la segunda potestad tribunicia desde el 25 de enero de $42^{42}$.

ERT 3 (lám. II, 2). Albarracín. En esta pieza se observa, con toda claridad, la presencia de cinco letras incompletas bajo la 1. 3 , cuya lectura no ofrece dudas y que, mal leídas, fueron ya señaladas por Leandro Martínez (PERCEVI), el informador de Uztarroz. La A. afirma primero que «nunca se tallaron completamente» y se inclina a pensar que fueron inscritas con posterioridad a la realización del epitafio, aunque duda, y termina sugiriendo después, que pudieran ser «el inicio erróneo de la inscripción de alguna fórmula». Más sencillo es considerarlas parte integrante del epígrafe -un examen atento de las mismas no arroja razones para dudar de su autenticidad-, cuyo soporte está evidentemente roto por la parte inferior. Habida cuenta de la rareza del gentilicio de la difunta, Ofillia ${ }^{43}$, resulta tentador y además coherente con la lectura deficiente de L. Martínez, suponer que en la línea 5 figuraba el nomen de la dedicante y que éste fuera Pescennia. La lectura, presentando subrayado el texto perdido, pero atestiguado por la tradición,

\footnotetext{
${ }^{40}$ Lavaña, p. 148.

${ }^{41}$ D. Kienast, Römische Kaisertabelle, Darmstadt, 1990, p. 228 .

${ }^{42}$ Kienast 1990 (cit. n. 41), p. 91.

${ }^{43}$ Para las variantes de este nomen ver H. Solin y O. Salomies, Repertorium nominum gentilium et cognominum Latinorum, Hildesheim, 1988, p. 131.
} 
quedaría así: Ofillia•Fuslça $\bullet a n($ norum) $\bullet L X X \quad \mid$ $\underline{h(i c) \cdot s(\text { ita) } \bullet e(s t) ~ \mid ~ P e s c e[n n i a ~ ?---] ~ I ~-. .-.-. ~ D a d a ~}$ la presencia del marco moldurado creo preferible fecharla a partir de mediados del siglo I d. E. mejor que a partir de $1 \mathrm{~d}$. E.

ERT 4 (lám. II, 3). Albarracín. Su presencia en el exterior de la torre de la catedral fue señalada por Lavaña junto a ERT 3, indicando «Pouco apartada desta pedra, está outra prolongada, toda escripta de Letras Romanas, maês taõn gastadas, \& Comidas do tempo, que nem huã palavra se pode ler» ${ }^{44}$. Ésta parece ser también la mencionada por Cornide (ver CIL II 3171). Se trata de una pieza de texto inédito hasta la edición de Navarro y de lectura muy difícil debido a la extremada erosión de la superficie. La A. se inclina por la versión $[---] \mathrm{O}+[---]$ INO an(norum) $\hat{X} X I$ P(ublii)? Fanni(i)? I F[ir]mani ? filio Âemiliâe | Aụ[itae ---]++++E | [---] | ---, que resulta, a mi juicio, poco satisfactoria, pues cabe dar una lectura más completa, que tuvimos oportunidad de establecer en 1990 conjuntamente con F. Marco.

Si nos circunscribimos a las letras más legibles, el texto quedaría así:

\section{[- A]ṇniọ Qụi ! +rc.6+ \\ [.] ạno an(norum) XXI I Q(uinti) Aṇni Firmani filio Âemiliâe \\ Aui++ậẹ + Q(uintus) Âemiliụs +++ \\ 5 +c. $5 / 6+$ ị ș +c. $4+$}

A pesar de las dificultades, el sentido del epígrafe parece claro. Está dedicado por un $Q$ (uintus) Âemiliụs, de cognomen incompleto -probablemente terminado en -is-, quizás un liberto, si es que las tres letras poco legibles del final de la 1.4 pueden resolverse en la forma + ! ! (bertus). Los difuntos son dos: uno el joven Annius de veintidós años y cognomen ilegible, al parecer inscrito en la tribu Quirina (no puede descartarse la lectura Qụịṇ̣̣ạ + c.3+), hijo de Q. Annius Firmanus, y la segunda una Aemilia, probablemente Auiạnạ de cogno$m e n^{45}$, tras la que parece constar una ụ, quizás inicial de u(xori), que podría ser la patrona del dedicante, en cuyo caso la letra desvaída, que figura en 1. 4 ante las letras que hemos interpretado !̣ (bertus), quizá pudiera entenderse ṃ(ulieris). La

\footnotetext{
${ }^{44}$ Lavaña, p. 148.

${ }^{45}$ El cognomen Auita que propone la A. no colma el espacio disponible. Un repertorio de los cognomina atestiguados en Hispania que encajan con el texto conservado, en J. M. Abascal, Los nombres personales en las inscripciones latinas de Hispania, Murcia, 1994, p. 292.
}

posible presencia de un individuo adscrito a la tribu Quirina contrasta con la habitual en la región, la Galeria, y podría indicar una origo foránea de esta familia. No obstante, debe recordarse que no tenemos constancia de cuándo fue privilegiada esta zona de la Serranía de Albarracín y que los testimonios de la tribu Galeria comprobados en el epitafio conservado en Calomarde no demuestran una municipalización preflavia del territorio. Datable a fines del siglo I o durante el II d. E.

ERT 7 (lám. IV, 6a-b). Alcañiz. No comparto del todo la lectura del texto que proporciona la A., [---] Optạ[. ---]A[---] an(norum) । [---]++[---]po(suit), en el que, aunque no mejore sensiblemente la comprensión del texto, creo posible leer algunas letras más, Optạ[-c. 3-]A+AN I SE[-c. 5-]++PO, que hacen inseguros los suplementos que la $A$. propone al final de la $1.1^{\mathrm{a}}$, an(norum), y al final de la $1.2^{\mathrm{a}}$, po(suit). En cuanto a su datación -que conlleva la de las aras anepígrafas ERT 29 y $30-$ la A. propone como fechas límite los años 251 y 400 por razones paleográficas que no me parecen de suficiente peso, máxime en un texto tan fragmentario.

ERT 11 (lám. VI, 9). Cella. Esta pieza, que la A. da por inédita y descubierta en 1978, apareció como tarde en los primeros años 50 según testimonio del presbítero Ángel Aguirre: «hace meses en un descubierto -esto es patio o corral- propiedad de don Santiago Gómez Lanzuela fue hallada otra lápida romana». Según la hija y el nieto del descubridor fue Mosén Ângel quien dio valor a este epígrafe encontrado al deshacer los pilares del corral sito en la c/ Vínculo 28, en el que todavía se encontraba en 1990 cuando lo vimos por primera vez, pero ingresado ahora en el Museo de Teruel, al que, generosamente, lo ha donado D. Santiago Gómez Lanzuela. Se trata de la mitad izquierda de un losa de caliza de 48 × (67.5) x 19 (no $\ll 32 \times 37 \times 20 »$ ) y campo epigráfico delimitado por un marco moldurado de 30.5 × 55.5 (no «35.2 x 45»). La altura de las letras es: $5\left(1.1^{\mathrm{a}}\right), 4.5\left(1.2^{\mathrm{a}}\right)$ y $4\left(1.3^{\mathrm{a}}\right)$ y la interpunción triangular con la punta hacia abajo.

$$
\begin{aligned}
& \text { G(aio)•Cor [neli----] } \\
& \text { G•Porç̣[i ----] } \\
& \text { Baebia C̣[---] }
\end{aligned}
$$

A. Aguirre, El Angel de los Silaos, Valencia, 1952, pp. 1011; F. Beltrán, «Hace dos mil años en Cella», Zaida (Cella) 16, 1996, 7-9

C. Corneli eF ...। C. Po ci C ...। BA IA C A ..., Aguirre; G•Cor[---] I G.Porc̣[---] I b(ene) merẹn[ti ---], Navarro. 
La lectura de la 1. $3^{\text {a }}$ que presenta M. Navarro ha de ser producto del efecto óptico que presenta su fotografía de la lám. VI: sobre la piedra la lectura Baebia no ofrece dudas (ver nuestra fig. 1). De la última letra de la línea sólo se observa un semicírculo cerrado por la izquierda. Según la versión de Aguirre cabría completar la 1. $3^{\mathrm{a}}$ en la forma Baebia C[--- ?]A[----] y suponer que en la $1.1^{\text {a }}$ tras el nomen figuraba la filiación. Este epitafio puede datarse por la presencia del marco moldurado encuadrando el texto en el último tercio del siglo i d. E. o en el siglo II.

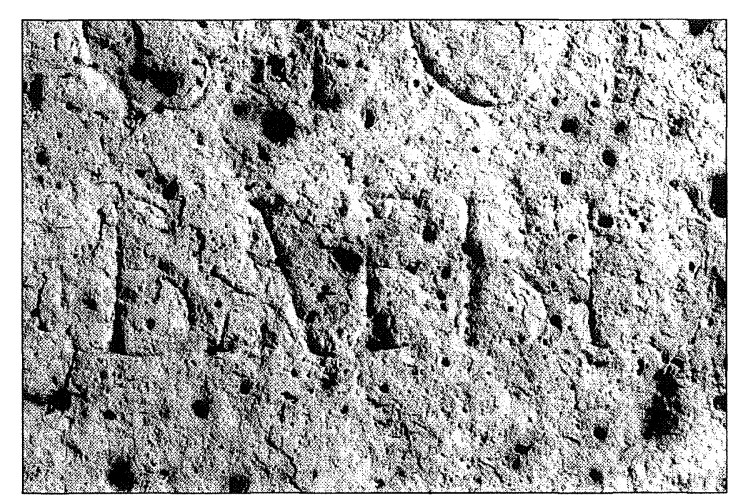

Fig. 1.-Ad núm. 11 (Cella).

ERT 13 (lám. VIII, 11). Hinojosa de Jarque. Falta la indicación en el texto de las interpunciones, muy desvaídas, pero perceptibles; y, sobre todo, es errónea la lectura de la primera palabra de la fórmula final que está abreviada ( $h$. y no hic), detalle que no se aprecia en la foto que presenta la A., tomada de Ventura (lám. 13), pero que es evidente. La lectura sería pues Valeria・M(arci)•f(ilia) | Seuera | Semproni Capito(nis) I h(ic) $\bullet$ s(ita) $\bullet e(s t)$, entendiendo -como apunta la A.- que Valeria Severa fuera la esposa de Sempronio Capitón.

ERT 14 (lám. VIII, 12). Hinojosa de Jarque. La pérdida de la parte izquierda (en la descripción de la A. hay una cierta confusión a propósito de cuál es la mitad conservada y cuál la perdida: «se conserva la parte izquierda», «falta toda la parte derecha», «la pérdida del lateral izquierdo») no obsta para comprobar que todos los cognomina están perfectamente alineados y que se conservan íntegros, como pudimos comprobar en la autopsia practicada junto con F. Marco en 1990, al permitirnos el propietario de la casa en donde se conserva, D. Remigio Gómez, levantar la gruesa capa de yeso que recubría su parte izquierda (cf. el estado anterior en Ventura, lám. 14). Los dos cognomina indígenas se conservan, por lo tanto, completos y deben leerse [---] Elguanus y [---] Dirtanus (y no [---]elguanus, [---]dirtanus). Como ya señalara Siles en $1985^{46}$, los nombres son celtibéricos y no ibéricos como afirma la A. (p. 168). Dirtanus se llamaba el individuo de Beligio enterrado en Ibiza (tirtanoś 1 abulokum । letontulnoś ke. belilkioś) y el nombre aparece también en otras inscripciones recogidas en los repertorios de Albertos y Holder así como en el gran bronce de Botorrita; en cuanto a Elguanus, conocíamos hasta ahora sólo paralelos ${ }^{47}$, pero consta también en el gran bronce de Botorrita en la forma elkuanos.

ERT 15 (lám. VIII, 13). La Iglesuela del Cid. Sobre la piedra figura Aelia $L \cdot f \cdot S u p e-$ vacat $1-$ sta (es decir Supe<r>sta), y no Supe•sta -la interpunción no se observa con claridad- ni Supe[r]sta, pues la letra $\mathrm{R}$ nunca se escribió. No hay constancia de tal cognombre ${ }^{48}$, que parece la forma femenina de Superstes ${ }^{49}$.

Sobre esta inscripción y ERT 16-19, cf. ahora CIL II², 14, 776-779.

ERT 21 (lám. XI, 18). La Puebla de Valverde. En el segundo campo epigráfico, muy fragmentario, que aparece a la derecha de la inscripción de Sergia Severa, la A. lee --- I + [---] | C[---] | A[---] | TI[---], pero se observan bajo la 1.4 indicios de la existencia de una línea más de texto. Respecto de la lectura ṬI[---], la segunda letra, además de una I, podría ser parte de otra incompleta: mejor leer $\mathrm{T}+[---]$. Las interpunciones en la inscripción de Sergia Severa son preferentemente circulares.

ERT 22 (lám. XI, 19a-b). Puertomingalvo. Otra discrepancia menor. Al comienzo de la la 1.4 , en donde la A. lee OS, es decir Propinqlos, puede observarse un trazo oblicuo (no se aprecia en la foto de la A.; pero ver nuestra fig. 2), que permite leer Propinqlus, forma más habitual para Propinquus.

ERT 24. Rubielos de Mora. De este epígrafe perdido Lavaña señala que «as letras naõ saõ das muy perfeitas principalmente algums L. que saõ

$46 \mathrm{~J}$. Siles, «Celtismo y latinización: la estela de Ibiza y una inscripción latina de Hinojosa de Jarque; sobre la mención de origo en las inscripciones celtibéricas», Serta gratulatoria in honorem J. Régulo, vol.1, Filología, La Laguna, 1985 , pp. 675-696; también Ventura, p. 251

${ }^{47}$ M. L. Albertos, La onomástica personal primitiva de Hispania tarraconense y bética, Salamanca, 1966, p. 113.

${ }^{48}$ Solin y Salomies 1988 (cit. n. 43), p. 409.

${ }^{49}$ I. Kajanto, The Latin cognomina, Helsinki, 1965, pp. 93-94 y 274. 


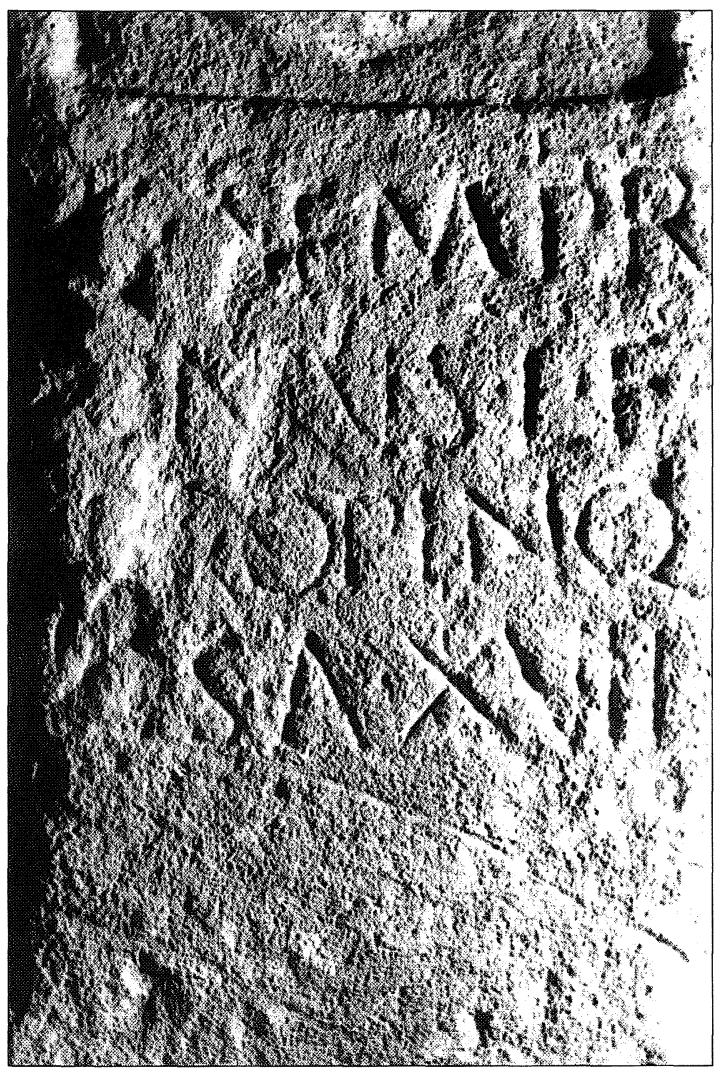

Fig. 2.-Ad núm. 22 (Puertomingalvo).

desta forma... ${ }^{50}$ indicando una $\mathrm{L}$ con el trazo horizontal oblicuo, similares, por tanto, a las que pueden verse en el epitafio de Aguatón conservado en Torremocha (ERT 25), y no en forma de $\mathrm{H}$ como indica la $\mathrm{A}$.

ERT 25 (lám. XII, 21). Aguatón. Convendría, quizá, indicar en el texto la interpunción silábica - angular en 1. 4, más bien circular en el resto-, en vez de hacer referencia a ella tan sólo en el aparato crítico. Es como sigue: $L($ ucio)• Cor•ne•li•o । Pa•ter•no | an•no•rum | $\cdot L X \mid$ Cor(nelius) -Dio•ge-Ines•pa•tro•-Ino•f(ecit).

ERT 26 (lám. XII, 22). Torres de Albarracín. Tuvimos la oportunidad de ver en 1991 este fragmento inédito cuya existencia nos comunicó amablemente J. Vicente, director del Museo de Teruel. El propietario de la casa en la que se conserva, D. Miguel Domínguez, c/ el Rovindero s/n, nos comunicó su lugar exacto de aparición, que no incluye la A., llamado la Masada de la Ollalda, sito a

\footnotetext{
${ }^{50}$ Lavaña, p. 157.
}

unos $3 \mathrm{~km}$. de Torres de Albarracín, en donde fue extraída a c. $50 \mathrm{~cm}$. de profundidad al realizar labores agrícolas en 1988.

$$
\begin{aligned}
& \text { [- P]ọmpei+[---] } \\
& \text { [---] Auito•Ṃ[---] } \\
& {[---]+[---]} \\
& ----- \\
& \text { [--- P]ọmpeiạ[n---] | [---] Ạuito[---] | [---]P++, Navarro. }
\end{aligned}
$$

Es posible que al final de la $1.1^{\text {a }}$ pueda leerse una $\mathrm{A}$; lo que es seguro es que en la 1. $2^{\mathrm{a}}$, tras Auito, se conserva un trazo oblicuo, correspondiente seguramente a una M. En cuanto a las letras de la 1. 3, una de ellas podría ser una $\mathrm{P}$, como sugiere la A., pero también una $\mathrm{E}$ por ejemplo, por lo que prefiero no manifestarme al respecto.

ERT 27 (láms. XIII y XIV). Peñalba de Villastar. Un comentario particular merece el tratamiento, muy desafortunado, que la A. da al conjunto de Peñalba. En primer lugar, puesto que su objetivo declarado es recopilar los epígrafes latinos (pp. 72 y 142), debería haber excluido de su corpus los once primeros (ERT 27A-L) que son célticos con seguridad (sólo cabe la duda parcial en ERT 27A), aunque redactados en alfabeto latino. No hay razón alguna para considerar que Calaitos, Turros / Turos, Aio, Guandos, Guandos Cotiriqum o Turros Caroqum / Cotiriqum sean textos latinos con un nominativo en -os arcaico (p. 143), cuando en la pared rocosa constan otros como Calaitos / uoramos ednoum, Turos / Caroqum (?) uiros ueramos o Turros Caroqum... (todos ellos recogidos por Gómez Moreno ${ }^{51}$ ), que la A. excluye por considerar célticos. El criterio de todos los especialistas que se han ocupado de la cuestión desde Cabré hasta Untermann pasando por Lejeune -cuyo Celtiberica de 1955, por cierto, denomina la A. sistemáticamente Celtiberia- ha sido el de considerarlos célticos y no hay fundamento alguno para alterar este punto de vista. En segundo lugar, la A. ha seguido la ordenación propuesta en 1949 por Gómez Moreno (como hicieran también Lejeune en 1955 y Tovar en 1959), ignorando su

${ }^{51}$ M. Gómez Moreno, «Suplemento de epigrafía ibérica», en Misceláneas. Historia. Arte. Arqueología, Madrid, 1949, pp. 326-330, núms. 5, 6 y 12 (= Gómez Moreno). Además se hace referencia a: J. Cabré, «La montaña escrita de Peñalba», BRAH 56, 1910, 241-280 (=Cabré ); A. Tovar, «Las inscripciones celtibéricas de Peñalba de Villastar», Emerita 27, 1959, pp. 349-365 (= Tovar), en colaboración con M. Gómez Moreno; J. Untermann, «En torno a las inscripciones rupestres de Peñalba de Villastar», Teruel 57-58, 1977, 5-25 (= Untermann). 
posición relativa sobre un farallón rocoso de más de un kilómetro en el que hay conjuntos diversos, de épocas muy variadas, en escritura ibérica y en alfabeto latino, en lengua céltica y en latín. Es evidente que la inscripción más significativa del conjunto es la dedicatoria en celtibérico a Lug (Gómez Moreno, núm. 1), circunstancia que hace más que verosímil que toda la montaña estuviera consagrada a esta divinidad, pero ignoramos si sólo a ella o también a otras; en consecuencia, titular ERT 27C «Calaitos a Lug», ERT 27H, «Guandos, fiel de Lug» y ERT 27I, «Otro devoto de Lug», aun siendo esta conexión cultual verosímil por el contexto general, no puede justificarse afirmando que estos grafitos se escribieron alrededor de la inscripción de Lug (p. 142), cuando de la descripción de Cabré se infiere con toda claridad que algunos de estos grafitos se encuentran, como mínimo, a decenas de metros de ella (ver la lám. I de Tovar entre pp. 356-357 con el emplazamiento de los conjuntos numerados por $\mathrm{Ca}$ bré). Por esta misma razón, es fundamental presentar los grafitos de acuerdo con un cierto orden topográfico, del que, por ejemplo, se desprende con claridad que en la ladera oriental de la montaña, en donde se emplazan los versos virgilianos, son raros los grafitos antiguos y no hay constancia de ninguno que sea con seguridad celtibérico, mientras que, conforme se progresa hacia el Norte, se adensan los redactados en esta lengua hasta hacerse predominantes más allá del corral para ganado (núm. 13 de la vista de Tovar, lám. I). Finalmente, la redacción de estas fichas reunidas en ERT 27 por la A. se ha realizado con suma ligereza, pues, además de lo dicho, falta un buen número de los dibujos de Cabré o Gómez Moreno correspondientes a los grafitos perdidos o ilocalizables; se omiten las dimensiones de los conservados ${ }^{52}$ y los números de inventario de los custodiados en el Museo de Barcelona (los datos que más abajo hago constar son los obtenidos en la autopsia practicada en 1994, gracias a la amabilidad y eficacia de $\mathrm{D}^{\mathrm{a}}$ Teresa Carreras) ${ }^{53}$; se reflejan

${ }^{52}$ Como dimensiones se suministra reiteradamente «100500/400», que debe corresponder a un tracto -que no a la totalidad- de la pared rocosa, y se asigna a los diferentes grafitos, números cuyo sentido no queda claro tras las entradas Campo epigr. y Fragmento $(s)$.

${ }^{53}$ 27B (campo epigráfico: 7 x 20; letras: 3-4 y 6; Museo Arqueológico de Barcelona, núm. inv. 28.310); 27C (campo epigráfico: 14 x 38; letras: 7-9; Museo Arqueológico de Barcelona, núm. inv. 28.311); 27D y E (dimensiones de la piedra arrancada: 6 × 16,5;27D: 5 x 10 del campo epigráfico, 4 de las letras; 27E: 2,5 x 6,5 del campo epigráfico, 2,5 de las letras; Museo Arqueológico de Barcelona, núm. inv. 28.314); $27 \mathrm{G}$ y $\mathrm{H}$ (dimensiones de la piedra arrancada: 10 x 38,5; letras: $4-4.5$ en $27 \mathrm{G}$ y $3-9$ en $27 \mathrm{H}$; Museo Arqueológico de Barcelona, núm. inv. 28.313); 271 (72 de longitud, según varios textos de manera incorrecta (particularmente ERT 27J, 27K, 27M, 27P) y son frecuentes los errores en las referencias bibliográficas (particularmente a las obras de Cabré y Gómez Moreno).

A los grafitos con seguridad o presumiblemente latinos pueden hacerse las siguientes observaciones:

-27L (lám. XIV, 27). Las iniciales D M, descubiertas por $\mathrm{F}$. Marco, son interpretadas por la $\mathrm{A}$. en la forma $D(e o) M$ (aximo), un desarrollo posible, pero en absoluto seguro (por qué no Deo Magno o, incluso, Deo Marte o Mercurio, dos divinidades clásicas con frecuencia asimiladas con dioses vernáculos en la Céltica), por lo que debería figurar con interrogantes. El desarrollo que la A. atribuye a Marco 1986 en el aparato crítico no es propuesto por éste en el lugar indicado.

-27M (lám. XIV, 28). En la transcripción de los famosos versos de Virgilio Tempus - erat • quo • prima $\cdot$ quies $\cdot$ mortalibus $\cdot$ aegris $\bullet$ inc[---], correspondientes a Aen. 268-269 -y no sólo a 268- se ha omitido la quinta palabra, quies.

-27 O. Este texto, que no ha sido visto desde Cabré y del que la A. no da ilustración, fue leído por Tovar AGILIS ANNIMAI y por la A. Agilis An\{n\}imal. Sin embargo, si la primera palabra parece clara, todo lo contrario ocurre con la segunda, por lo que creo arriesgado dar una lectura segura más allá de ésta (ver nuestra fig. 3): Agilis $\mathrm{AN}++\mathrm{M}++$

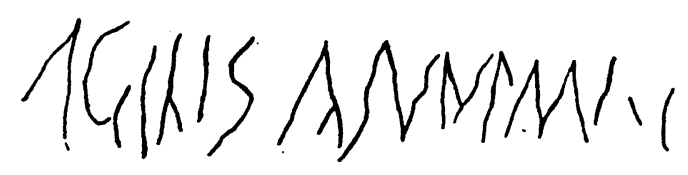

Fig. 3.-Ad núm. 27 O (Gómez Moreno 1949, p. 328, núm. 14).

-27P. Muy discutible me parece considerar este grafito como latino, siguiendo la opinión de Lejeune que leyó, un tanto imaginativamente, DAVN[i]IAS QVIS (?), suponiendo que se refiriera a los Daunios; Tovar, a cambio, más respetuoso con el calco de Gómez Moreno entendió DAVI[---] I ASQIES, y

Gómez Moreno); 27J (según Untermann, ocupa una franja de $25 \times 70$ ); 27 M-N (6 x 28, según Cabré; 70 de longitud, según Gómez Moreno; 1-3 x 35 para la $1.1^{\text {a }}$, según Tovar); 27) (23 cm. de longitud, según el calco de Cabré); según 27Q (23 cm. según Gómez Moreno) 
nosotros preferimos no aventurarnos más allá de esta lectura (ver nuestra fig. 4): $D+A++[---]$ । $\mathrm{ASQ}+++\mathrm{S}$

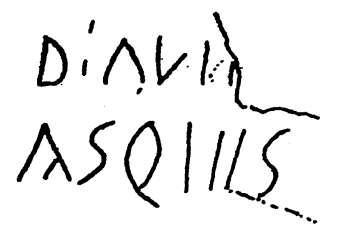

Fig. 4.-Ad núm. 27 P (Gómez Moreno 1949, p. 328 , núm. 16)

-27Q (lám. XIV, 29). La A. sigue el parecer de Mallon, según quien nos encontraríamos ante un alfabeto en el que, a partir de la foto de Cabré publicada por Tovar, se leería ABCDEFGHIKLMNO. Si la secuencia inicial, $A B C$, parece clara, no lo es en absoluto la siguiente, DEFGH, ni la última, KLMNO, tras el trazo vertical que se interpreta como I, mucho menos, siendo las dos últimas letras imperceptibles en la fotografía, por lo que preferimos no manifestarnos acerca de la interpretación de este grafito: $\mathrm{ABC}+++\mathrm{I}++$

En lo tocante a ERT 27A-K, se trata, como ya hemos indicado, de rótulos célticos con total seguridad $\mathrm{y}$, en consecuencia, deberían haber sido excluidos del catálogo. De cualquier forma y dejando al margen ciertas inexactitudes en las referencias bibliográficas y omisiones de las medidas, hay también algunas precisiones pertinentes sobre la presentación de los textos. En 27A y pese a la lectura de Untermann (Marcos Masmi f | Primi+++[---] | [..]llos [...]oq, que la A. corrige acertadamente en 1 . $3^{\mathrm{a}}$ en la forma [---]rros), el calco publicado por Gómez Moreno (cf. nuestra fig. 5) contiene mucho más texto, cuya lectura a nuestro juicio podría ser: $\mathrm{M}+\mathrm{rcos} \cdot \mathrm{Masmi}+\mid \mathrm{DEN}++\mathrm{N} \mathrm{D}+\mathrm{IM}+$ PENERI I [Tu]rros $\cdot$ Caroq(um). Hay que subrayar que la forma Marcos -si ésta fuera la restitución adecuadano tiene por qué ser considerada latina, pues el uso del aparente prenombre Marcus como nombre personal en inscripciones latinas procedentes de diversos puntos de la Hispania indoeuropea ${ }^{54}$, induce a pensar que existía un nombre céltico homófono, circunstancia que ahora parece confirmar el gran bronce de Botorrita en el que aparece el nombre markos. Por lo tanto resultaría más que incongruente la combinación de una forma flexiva céltica con una filiación de tipo latino (Masmi f.), en la que además la interpretación del nombre como una expresión inco-

\footnotetext{
${ }^{54}$ Abascal 1994 (cit. n. 45), p. 414
}

rrecta de Maximi es una mera conjetura. El carácter céltico de la fórmula onomástica de la $1.3^{a}$ es transparente y, además, el grafito se ubica en una zona de la pared en la que predominan los letreros vernáculos. En cuanto a $27 \mathrm{~J}$, una de las inscripciones descubiertas por Untermann en Peñalba, que la A. transcribe en la forma Turros Carorum I [--- $\mathrm{CO}^{-}$ tiriqum, el paleohispanista alemán indica en la primera línea la posibilidad de leer Caroqum (p. 20), que parece más acorde con la formación celtibérica de los nombres familiares e insiste en que la piedra aparece a la izquierda intacta y vacía de signos (p. 16), por lo que debe suprimirse la indicación de laguna al comienzo de la $1.2^{\mathrm{a}}$ y leer: Turros Caroqum I Cotiriqum. La presencia de dos nombres familiares en una fórmula onomástica es ciertamente excepcional y hace sospechosa la lectura, pero podría tener ahora algún paralelo en el gran bronce de Botorrita. 27K es otro de los descubrimientos de Untermann, cuyo texto, muy poco legible, diría, en su opinión, [---]IRRIVS, señalando el posible paralelo Irricorum (CIL II 2843), si bien del dibujo que publica se colige más bien [---]|RRI+[---], pero, en ningún caso, IRRIVS que es la versión que recoge la A.

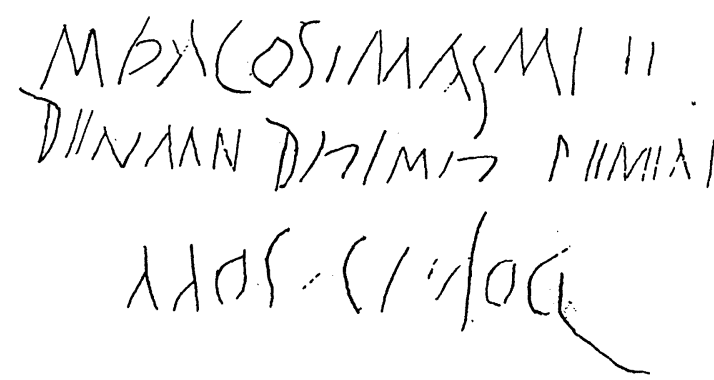

Fig. 5.-Ad núm. 27A (Gómez Moreno 1949, p. 326, núm. 1).

En lo que toca a la cronología del conjunto, contamos con un terminus post quem en el verso virgiliano que recoge ERT 27M y que, por lo tanto, obliga a datar el grafito a partir de comienzos del siglo I d. E. Conviene subrayar que la grafía de este epígrafe no difiere de la presente en los de lengua céltica y en la mayor parte de los latinos antiguos, por lo que la datación de unos y otros debe ser relativamente homogénea. De hecho, la utilización del alfabeto latino para escribir en celtibérico puede datarse en los años inmediatemente anteriores al principado de Augusto ${ }^{55}$, quizás a mediados del si-

\footnotetext{
${ }^{55}$ Beltrán 1995 (cit. n. 13), p. 181.
} 
glo i a. E. como pronto ${ }^{56}$, mientras que el uso escrito de la lengua celtibérica no parece rebasar los primeros decenios del siglo I d. E., por lo que los grafitos en lengua céltica de Peñalba así como los más antiguos de los latinos - a juzgar por la paleografíano creo que puedan ser posteriores al siglo i d. E. La A. se inclina por datar los que contienen nombres célticos entre 24 a. E. y 70 ó 100 d. E. -no justifica la variación en el terminus ante quem- (ERT 27A$\mathrm{K}$ ), mientras que asigna al verso virgiliano y su presunta contestación una cronología entre 51 o 71 y 200 , cuyo término posterior parece, por las razones paleográficas ya comentadas, excesivo.

ERT 31 (lám. XVI, 33). Puertomingalvo. Esta estela más que anepígrafa es de texto ilegible. El epígrafe constaba de tres líneas: al final de la primera puede leerse una $\mathrm{A}$.

\section{$* * *$}

En definitiva y pese a los indudables méritos que este nuevo corpus encierra, incluidos tres epígrafes inéditos y otro poco conocido así como datos de interés a propósito de otros ya publicados, el balance final no puede ser del todo positivo. Es muy de lamentar que el nacimiento de la serie que esta monografía inaugura y la sólida formación que la A. demuestra en muchos lugares de la misma se hayan visto ensombrecidas por la apresurada conclusión del trabajo. Y no se trata tanto de que algunas lecturas sean discutibles, pues al fin y al cabo cuando los textos entrañan problemas, el editor no hace otra cosa que plantear una lectio de la que no pueden excluirse alternativas; ni siquiera de la omisión de algunos epígrafes ya publicados previamente; sino de la impresión de precipitación que se desprende de muchas de las fichas de este catálogo -incluida, en varios casos, la presentación del texto-, sobre todo en el caso de Peñalba, cuyo tratamiento no supone mejora alguna respecto de las publicaciones previas, sino todo lo contrario. Un corpus debe distinguirse por la solidez en la presentación de los datos objetivables como son medidas, descripción de las piezas, lugares de hallazgo, referencias bibliográficas o el propio texto cuando la lectura es clara, y en este terreno, por desgracia, las abundantes erratas, omisiones e inexactitudes generan desconfianza en el lector y, a la postre, reducen notablemente el valor del estudio. La culminación de este trabajo hubiera requerido de una corrección más cuidadosa, acompañada en varios casos de la imprescindible revisión o examen directo de las piezas. A buen seguro que, en tal caso, el resultado final hubiera estado a la altura de la probada competencia de su autora.

${ }^{56} \mathrm{~J}$. Untermann, «Epigrafía indígena y romanización en la Celtiberia», Beltrán, ed., 1995 (cit. n. 27), p. 199. 